\title{
Medication prescribing errors in the intensive care unit of Jimma University Specialized Hospital, Southwest Ethiopia
}

This article was published in the following Dove Press journal:

Journal of Multidisciplinary Healthcare

28 October 201I

Number of times this article has been viewed

\author{
Asrat Agalu' \\ Yemane Ayele ${ }^{2}$ \\ Worku Bedada ${ }^{2}$ \\ Mirkuzie Woldie ${ }^{2}$ \\ 'Wollo University, College of Health \\ Sciences, Department of Pharmacy, \\ Dessie, Ethiopia; ${ }^{2}$ Jimma University, \\ College of Public Health and Medical \\ Sciences, Jimma, Ethiopia
}

Background: A number of studies indicated that prescribing errors in the intensive care unit (ICU) are frequent and lead to patient morbidity and mortality, increased length of stay, and substantial extra costs. In Ethiopia, the prevalence of medication prescribing errors in the ICU has not previously been studied.

Objective: To assess medication prescribing errors in the ICU of Jimma University Specialized Hospital (JUSH), Southwest Ethiopia.

Methods: A cross-sectional study was conducted in the ICU of Jimma University Specialized Hospital from February 7 to April 15, 2011. All medication-prescribing interventions by physicians during the study period were included in the study. Data regarding prescribing interventions were collected from patient cards and medication charts. Prescribing errors were determined by comparing prescribed drugs with standard treatment guidelines, textbooks, handbooks, and software. Descriptive statistics were generated to meet the study objective.

Results: The prevalence of medication prescribing errors in the ICU of Jimma University Specialized Hospital was 209/398 (52.5\%). Common prescribing errors were using the wrong combinations of drugs $(25.7 \%)$, wrong frequency (15.5\%), and wrong dose (15.1\%). Errors associated with antibiotics represented a major part of the medication prescribing errors $(32.5 \%)$.

Conclusion: Medication errors at the prescribing phase were highly prevalent in the ICU of Jimma University Specialized Hospital. Health care providers need to establish a system which can support the prescribing physicians to ensure appropriate medication prescribing practices.

Keywords: medication error, prescribing error, intensive care unit

\section{Introduction}

Medication errors (MEs) are major issues in health care and are probably one of the most common types of medical errors. ${ }^{1,2}$ These events may occur due to professional practice, health care products, and procedures such as prescribing, dispensing, and administration. ${ }^{2}$ High error rates with serious consequences are most likely to occur in intensive care units but errors are minimized in the presence of intensivists. ${ }^{1,3}$ MEs are more common in ICUs, probably because of polypharmacy and a more stressful environment than other wards in the hospital. ${ }^{1,4-7}$ The majority of errors are not due to reckless behavior on the part of health care providers, but occur as a result of the speed and complexity of the medication use cycle, combined with faulty systems, processes, and conditions that lead people to make mistakes or fail to prevent them. ${ }^{1,4-6,8}$

Prescribing errors in critical care units are frequent, serious, and expected, since these patients are prescribed twice as many medications as patients outside critical
Correspondence: Mirkuzie Woldie Jimma University, College of Public Health and Medical Sciences, PO Box 1637, Jimma, Ethiopia

Tel +25I 47। I 22738

Fax +25 I 47I I I952I

Email mirkuziewise@gmail.com which permits unrestricted noncommercial use, provided the original work is properly cited. 
care. ${ }^{1,6-7}$ More patients suffer a potentially life-threatening error at some point during their stay than patients in other hospital wards due to their decreased physiological reserves which increases the risks of harm from medication-related errors. ${ }^{7,9}$ Camire et al reported the point prevalence of medication errors in the ICU to be 10.5 per 100 patient-days, with the prescribing error rate being $54 \% .{ }^{7}$ However, there is wide variation in the definition of errors and the methods used to detect them. ${ }^{6-7,10}$ Factors contributing to the frequency of MEs include: unobtainable medical history since most patients in the ICU are sedated (unable to identify potential errors by themselves); multiple medications being received; most medications in the ICU being given intravenously, where calculation of infusion rates is often required; and insufficient staff numbers. ${ }^{1,10,11}$

The major consequences of MEs are patient morbidity and mortality. ${ }^{4-6}$ MEs can affect patients, families, and health care providers indirectly because of cost implications, prolonged hospital stays, and psychological impact, since errors erode public confidence in the health care service. ${ }^{1,6}$ However, data regarding MEs in Africa, ${ }^{12}$ especially in Ethiopia is scarce. Information regarding MEs in the ICUs of Ethiopian health institutions is absent.

Owing to the staffing structure in the ICU, the settings in which patients are managed, and the types of medications commonly used in the Ethiopian context, we expected the type and prevalence of MEs to be different from those reported in other studies. Prescribing error was specifically chosen for this evaluation because of the absence of any system to support prescribing physicians, who usually rely on their memory, to ensure correct prescribing practice. Therefore, this study was initiated to determine the prevalence and types of medication errors in the prescribing phase in the ICU of JUSH, Southwest Ethiopia.

\section{Methods}

\section{Study area}

A cross-sectional study was conducted from February 7 to April 15, 2011 in the ICU of JUSH, a teaching hospital located in Jimma, in Southwestern Ethiopia, $350 \mathrm{~km}$ southwest of the capital Addis Ababa. JUSH is the only referral hospital in the southwestern part of Ethiopia, with 450 beds and 558 health professionals, where a multidisciplinary team of diverse professionals provide a range of health care services for approximately 9000 inpatients and 80,000 outpatients each year. The ICU has six beds and serves critically ill patients from different departments of the hospital. Medication distribution is centralized and there is no floor-based decentralized pharmacy service currently available in the ICU. ${ }^{12}$

\section{Study subjects}

All medication-prescribing interventions by all prescribing physicians for all patients admitted to the ICU during the data collection period were included in this study. Data regarding prescribing of medications were collected from patient cards and medication charts using a pre-tested data collection format.

\section{Data collection process}

Data were collected, using a structured format, by two clinical pharmacy postgraduate students who were instructed on how to approach the patients and health care professionals to obtain data from patient cards and medication charts. The content included demographic variables, dates and times of prescription, name of the medication, dosage forms, doses, frequency, and duration of medications prescribed. Demographic information about patients was obtained from patient cards and medication charts. Diagnostic test results were used to determine the accuracy of diagnosis, and thus determine appropriate medications for each patient. Health professionals who prescribed the drugs were given unique identification numbers until the end of the data collection period to prevent bias.

Prescribing errors were determined by comparing prescribed drugs with national standard treatment guidelines, textbooks, handbooks, and software. ${ }^{13-24}$ Data were edited, coded, and entered into SPSS (Windows v 16.0; SPSS Inc, Chicago, IL). Descriptive statistics were computed to determine specific errors and the overall prevalence of prescribing error.

\section{Operational definitions}

Prescribing error: implies deviation of medication prescribing from standard practices (as indicated in national standard treatment guidelines, textbooks, handbooks, and software) excluding dosage form errors, illegible hand writing, and failure to authenticate the prescription with signature and/or date.

Complex regimen: prescription of more than three drugs to one patient at the same time.

Antibiotics: in this study, implies antibacterial drugs.

Wrong combination: implies drug interactions and therapeutic duplications.

Omission error: implies medications ordered without specifying dose/frequency/route.

Wrong frequency: implies drugs prescribed with a frequency greater or less than what is recommended. 
Wrong dose: implies the dose ordered by physician was higher or lower than what is recommended.

Wrong route: implies that the medication was prescribed to be given in a route other than the one recommended.

Wrong indication: implies the presence of incorrect indication and contraindications which were not noted by the prescribing physician.

\section{Ethical considerations}

Ethical clearance was obtained from the Ethical Review Board of Jimma University. Before the start of data collection, permission was obtained from the hospital management and written consent was obtained from respondents. Moreover, the names of patients and health professionals were replaced with codes to avoid individual identifiers.

\section{Results}

\section{Characteristics of interventions and participants}

This study included 398 physician drug prescriptions for 69 patients who were admitted to the ICU of JUSH during the study period. Those medication orders with illegible handwriting $(8.8 \%)$, failure to authenticate the medications with signature and date $(30.9 \%)$, and dosage form errors were not included in the definition of prescribing errors.

The majority of the 69 patients $(55.1 \%)$ were females, with $44(63.8 \%)$ of them aged $18-50$ years, and a mean age of $32.9( \pm 17.0)$ years. Fifty-four $(78.3 \%)$ of them were admitted to other wards before they were admitted to the ICU. Thirty-two $(46.4 \%)$ of the patients were unconscious and $49(71.0 \%)$ received a complex regimen, with the average number of medications per patient being $5( \pm 2.0)$ drugs. Patients stayed an average of $5.654( \pm 5.2)$ days in the ICU, until death or transfer to other wards. The average number of comorbid conditions per patient was $3 \pm 2.0$ (Table 1).

Twenty-seven physicians were involved in prescribing medications in the ICU during the data collection period. Almost all of the prescribers were in the age range 20-25 years and were males. Medical interns were most frequently involved in prescribing medications although they only had a 1-week-long stay in the ICU as part of their work experience in the internal medicine department (Table 2). About 13 (61.9\%) of the physicians were off duty $1-4$ nights per week but all of them took the day off following a night shift. The remaining eight (38.1\%) of the physicians had part-time work outside the hospital during the data collection period. Eleven (52.4\%) physicians had encountered at least one incident of medication error. Seven of them responded
Table I Characteristics of patients admitted to the ICU of JUSH, April 201 I ( $n=69)$

\begin{tabular}{lll}
\hline Characteristics & & Frequency (\%) \\
\hline Age & $<18$ years & $12(17.4)$ \\
& $18-50$ years & $44(63.8)$ \\
& $>50$ years & $13(18.8)$ \\
Sex & Male & $31(44.9)$ \\
& Female & $38(55.1)$ \\
State of patient & Conscious & $37(53.6)$ \\
& Unconscious & $32(46.4)$ \\
Regimen taken & Complex & $49(71.0)$ \\
& Not complex & $20(29.0)$ \\
State of admission & Emergency* & $15(21.7)$ \\
& From other wards & $54(78.3)$ \\
Length of ICU stay & $<4$ days & $28(40.6)$ \\
& $\geq 4$ days & $41(59.4 \%)$ \\
\hline
\end{tabular}

Note: *Emergency admission to the ICU implies that the patient was directly admitted to the ICU on arrival.

with self-intervention, and only two had reported to the appropriate senior physician.

\section{Medication errors}

Among the 398 drug prescriptions for the 69 patients, there were 209 prescriptions containing at least one error. This constitutes a prescribing error prevalence of $52.5 \%$ during the study period (67 days). This implies that on average there were more than three prescriptions with at least one error every day in the ICU while on average only one patient was admitted per day during the same period. Out of these errors, wrong combination, frequency, and dose of drugs accounted for $68(25.7 \%)$, 41 (15.5\%), and 40 (15.1\%), respectively. For 63 (23.8\%) of the

Table 2 Characteristics of physicians involved in prescribing medications in the ICU of JUSH, April 20II $(n=2 I)$

\begin{tabular}{lll}
\hline Characteristics & & Frequency (\%) \\
\hline Age & $20-25$ years & $17(80.9)$ \\
& $26+$ years & $4(19.1)$ \\
Sex & Male & $18(85.7)$ \\
& Female & $3(14.3)$ \\
On duty & Yes & $13(61.9)$ \\
& No & $8(38.1)$ \\
Qualification* & Resident I & $2(9.5)$ \\
& Resident II & $1(4.8)$ \\
Experience & Medical interns & $18(85.7)$ \\
& I week & $19(90.5)$ \\
Have part time work & 2 months & $2(9.5)$ \\
& Yes & $8(38.1)$ \\
Encountered MEs & No & $13(61.9)$ \\
& Yes & $11(52.4)$ \\
& No & $10(47.6)$ \\
\hline
\end{tabular}

Note: *Resident I and II are medical doctors in specialty training in the respective years. Medical interns are final year medical students practicing under the supervision of senior physicians.

Abbreviations: ME, medication error; ICU, intensive care unit. 


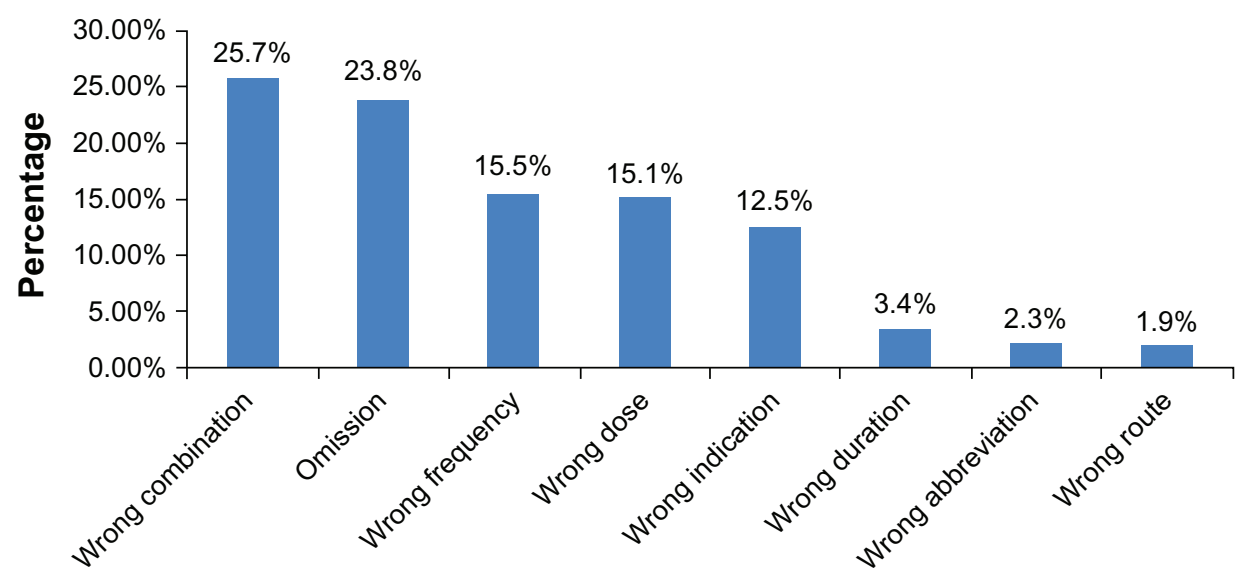

Category of medication prescribing errors

Figure I Medication prescribing error categories in the ICU of JUSH, April 201 I.

Abbreviation: ICU, intensive care unit.

medications prescribed, dose/frequency/route of administration and unit of measurement were omitted (Figure 1).

Drugs with prescribing errors were classified according to their therapeutic category. Antibiotics (32.5\%) and cardiovascular drugs $(26.3 \%)$ were the most common categories of drugs associated with prescribing errors followed by analgesic/antipyretics (9.6\%; Table 3$)$.

Taking specific drugs into consideration, diclofenac (7.7\%), ceftriaxone (7.2\%), and furosemide (6.2\%) were the three drugs most commonly associated with prescribing error (Table 4).

\section{Discussion}

Although the definition of prescribing error did not include illegible hand writing, lack of authentication, errors associated with dosage forms, and severity of error, the findings of this study shed light on the magnitude of the problem in the ICUs of hospitals in resource-limited settings. According to this study the frequency of medication prescribing errors

Table 3 Therapeutic category of medications with prescribing errors in the ICU of JUSH, April, 20I I

\begin{tabular}{ll}
\hline Drug category & Frequency (\%) \\
\hline Antibiotics & $68(32.5)$ \\
Cardiovascular drugs & $55(26.3)$ \\
Analgesic/antipyretics & $20(9.6)$ \\
Anticonvulsants & $13(6.2)$ \\
Opioid & $12(5.7)$ \\
Gl drugs & $10(4.8)$ \\
CNS drugs & $9(4.3)$ \\
Others* & $22(10.5)$ \\
Total & $209(100)$ \\
\hline
\end{tabular}

Note: *Antiparasitic, anticoagulants, antithyroids, corticosteroids, electrolytes, antidiabetics.

Abbreviations: ICU, intensive care unit; CNS, central nervous system; $\mathrm{Gl}$, gastrointestinal. was 209 (52.5\%). This finding is a relatively low frequency compared to the results of an earlier study involving 205 ICUs in 29 countries. $^{7}$ Conversely, there were higher frequencies of prescribing errors in this study than those voluntarily reported in: the intensive care and general care units in Pennsylvania in the US; a before-and-after study in a surgical ward in London; a prospective cohort study in Japan; and a multicenter prospective cohort study of seven ICUs in two hospitals in Rabat. ${ }^{25-28}$ The difference could be due to differences in definitions of errors, methods used to detect errors, level and type of ICUs, and availability of facilities for patient care. However, the higher frequency of errors in the ICU of JUSH even after excluding errors related with illegible hand writing, lack of authentication, and dosage form might be related to lack of sufficiently trained staff, absence of a pharmacist in the health care team, absence of

Table 4 Top ten drugs associated with prescribing error in the ICU of JUSH, April, 20I I

\begin{tabular}{ll}
\hline Drugs & Frequency (\%) \\
\hline Diclofenac & $16(7.7)$ \\
Ceftriaxone & $15(7.2)$ \\
Furosemide & $13(6.2)$ \\
Chloramphenicol & $11(5.3)$ \\
Gentamycin & $10(4.8)$ \\
Ampicillin & $10(4.8)$ \\
Enalapril & $9(4.3)$ \\
Aspirin & $8(3.8)$ \\
Pethidine & $8(3.8)$ \\
Phenytoin & $8(3.8)$ \\
Diazepam & $8(3.8)$ \\
Others* & $93(44.5)$ \\
Total & $209(100)$ \\
\hline
\end{tabular}

Note: *Diazepam, cimetidine, dopamine, hydrocortisone, insulin. Abbreviation: ICU, intensive care unit. 
Table 5 Examples of medication prescribing errors in the ICU of JUSH, April, 20I I

\section{Faulty use of medications observed \\ Ceftriaxone 2 g IV BID for 18 days instead of 14 days to treat \\ community-acquired pneumonia. \\ Ceftriaxone I g IV BID for a child to treat sepsis instead of $500 \mathrm{mg}$ IV BID. \\ Ciprofloxacin $2 \mathrm{~g}$ IV BID to treat urinary tract infections instead \\ of $500 \mathrm{mg}$ BID. \\ Crystalline penicillin was initially prescribed on once daily (Od) basis instead of Q4 hours. \\ Cloxacillin $625 \mathrm{mg}$ IV QID was prescribed for a child to treat infection secondary to burns, instead of $62.5 \mathrm{mg}$ IV QID. \\ Diclofenac $75 \mathrm{mg}$ QID was prescribed for head injury for pain where there was a history of gastrointestinal bleeding, instead of $75 \mathrm{mg}$ TID. Magnesium sulfate $2.5 \mathrm{mg}$ IM Q4 hr was given for Eclampsia instead of a $4 \mathrm{~g}$ loading dose over 10 minutes followed by I $\mathrm{g}$ maintenance dose per hour. \\ Metronidazole $500 \mathrm{mg}$ IV TID was given for a child to treat sepsis instead of $250 \mathrm{mg}$ IV TID. \\ Propranolol $40 \mathrm{mg}$ PO BID was prescribed with atenolol $25 \mathrm{mg}$ PO OD to treat hypertensive encephalopathy where either drug is enough. \\ Tramadol $50 \mathrm{mg}$ IM TID was prescribed with pethidine $50 \mathrm{mg}$ IM TID where either drug is enough. \\ Abbreviations: IV, intravenous; BID, twice daily; QID, four times daily; TID, three} times daily; IM, intramuscular; PO, orally; OD, once daily.

a closed-loop electronic prescribing mechanism, and lack of required medical facilities in the ICU.

In this study, the most common types of medication prescribing errors were the wrong combination of drugs (25.7\%), dose/frequency/route/unit omitted (23.8\%), frequency (15.5\%) and dose (15.1\%), wrong indication (3.4\%), wrong abbreviations $(2.3 \%)$, and wrong route (1.9\%). Omission errors, wrong indication, and wrong dose were lower than in a study from London, ${ }^{29}$ probably due to low number of total errors in the other study. Frequencies of wrong dose and indication were higher than findings in a study from London while they were lower than those from Pennsylvania in the US. ${ }^{25,26}$ Such errors could result in toxicity/treatment failure in settings which lack therapeutic drug monitoring as is the case in our study area.

According to this study, the three most common categories of drugs encountered in prescribing errors were antibiotics (32.5\%), cardiovascular drugs (26.3\%), and analgesic/antipyretics $(9.6 \%)$. This was different from what was reported from Pennsylvania, USA, where opioid analgesics (13.2\%) were the most common category followed by $\beta$-lactam antimicrobials (8.4\%) and blood coagulation modifiers (6.4\%). It is also worth noting that the frequency of error among the top-rating drug categories in our study is much higher than those in the Pennsylvania study. The frequency of errors associated with opioid analgesics $(5.7 \%)$ was quite low in this study and there were no errors recorded in relation to blood coagulation modifiers. ${ }^{26}$ The difference might be attributed to differences in the types of cases admitted to the ICU, and comorbid conditions in the patients.

Different studies have proposed different strategies to prevent medication errors. These include optimizing the medication process, eliminating situational risk factors, oversight and error interception, and interdisciplinary teams. ${ }^{5-7,30}$ Many studies have emphasized inclusion of the clinical pharmacist in the health care team to help to identify MEs, contribute to the rationalization of drug therapy, and potentially prevent negative consequences, leading to increased medication safety., $5,31,32$ Raising awareness of risk factors, medication reconciliation, prescribing vigilance among physicians, and good handover technique between physicians were also recommended. ${ }^{7}$

Finally, it must be noted that this study did not explore the severity of errors, outcome of treatment or reasons for errors. Patients' weight and dosage forms were often omitted from patient cards and medication charts. Illegible handwriting and prescriptions which were not signed and dated were not considered as errors. The use of guidelines rather than clinical opinions to determine error, and the small number of patients included in the study must also be noted.

In conclusion, medication errors at the prescribing phase were highly prevalent in the ICU of the JUSH. The errors reported in this study clearly show that there are multiple causes for prescribing errors in the ICU of JUSH. With the increasing complexity of care in critically ill patients, organizational factors such as the absence of quality assurance measures, error reporting systems, and routine checks could have contributed to the errors reported here. The lack of close supervision for the prescribing medical interns, along with the absence of the clinical pharmacist in the ICU team, could have made things worse. Hospital managers should strive to create better awareness about the possibility of medication errors at the prescribing phase among health care professionals. Introduction of quality assurance measures and routine checks with close supervision of the prescribing intern physicians are strongly recommended. We also recommend the inclusion of the clinical pharmacist in the health care team of the hospital in general and the ICU in particular.

\section{Disclosure}

The authors report no conflicts of interest in this work.

\section{References}

1. Corrigan JM, Donaldson MS, Kohn LT, et al; for Institute of Medicine. To Err is Human: Building a Safer Health System. Washington, DC: National Academy Press, 1999. Available from: www.iom.edu. Accessed November 15, 2010. 
2. Counsel of Europe. Partial agreement in the social and public health field. Survey on medication errors. Nov 2002. Available from: http:// www.coe.int/t/e/social_cohesion/soc-sp/Survey\%20med\%20errors.pdf. Accessed October 15, 2010.

3. ICU physician staffing. Fact sheet. The Leapfrog group for patient safety rewarding higher standards. Available from: http:/www.leapfroggroup. org/media/file/FactSheet_IPS.pdf. Accessed November 15, 2010.

4. Fahimi F, Sistanizadb M, Abrishami R, Baniasadi S. An observational study of errors related to the preparation and administration of medications given by infusion devices in a teaching hospital. Int J Pharm Res. 2007;6(4):295-299.

5. Williams DJP. Medication errors. J R Coll Physicians Edinb. 2007;37: 343-346.

6. Moyen E, Camiré E, Stelfox HT. Clinical review: Medication errors in critical care. Crit Care. 2008;12(2):208.

7. Camiré E, Moyne E, Stelfox HT. Medication errors in critical care: risk factors, prevention and disclosure. CMAJ. 2009;180(9):936-943.

8. Barker KN, Flynn EA, Pepper GA, Bates DW, Mikeal RL. Medication errors observed in 36 health care facilities. Arch Intern Med. 2002; 162(16):1897-1903.

9. Mohamed N, Gabr H. Quality improvement techniques to control medication errors in surgical intensive care units at emergency hospital. J Med Biomed Sci. 2010:24-35.

10. Wilmer A, Louie K, Dodek P, Wong H, Ayas N. Incidence of medication errors and adverse drug events in the ICU: a systematic review. Qual Saf Health Care. 2010;19(5):e7.

11. Goldstein RS. Management of the critically ill patient in the emergency department: focus on safety issues. Crit Care Clin. 2005;21(1): 81-89.

12. Jimma University Specialized Hospital. Available at: http://www.ju.edu. et/node/94. Accessed on November 15, 2010.

13. Drug Administration and Control Authority of Ethiopia. Standard treatment guidelines for general hospitals. 2nd ed. Addis Ababa, Ethiopia: Chamber Printing House; 2010.

14. Drug Administration and Control Authority of Ethiopia. Ethiopian National drug formulary. 1st ed. Addis Ababa, Ethiopia, 2008.

15. Henry GP, Gilbert RP. Handbook of Drugs in Intensive Care: An A-Z Guide. 3rd ed. New York: Cambridge University Press; 2006.

16. Fauci AS, Kasper DL, Longo DL, et al. Harrison's Principles of Internal Medicine. 17th ed. New York: McGraw-Hill; 2008.

17. Kliegman RM, Behrman RE, Jenson HB, Stanton BF. Nelson Text Book of Pediatrics. 18th ed. Philadelphia, PA: Saunders Elsevier; 2007.
18. Berek JS. Berek and Novak's Gynecology. 14th ed. Philadelphia, PA: Lippincott Williams and Wilkins; 2006.

19. Anderson PO, Knoben JE, Troutman WG. Handbook of Clinical Drug Data. 10th ed. New York: McGraw-Hill, Medical Publishing Division; 2002.

20. Susla GM, Suffredini AF, McAreavey D, et al, editors. Handbook of critical care drug therapy. 3rd edition. Philadelphia, PA: Lippincott Williams and Wilkins; 2006.

21. Dipiro JT, Talbert RL, Yee GC, et al, eds. Pharmacotherapy: A Pathophysiologic Approach. 7th ed. New York: McGraw-Hill, Medical Publishing Division; 2008.

22. Koda-Kimble MA, Young LY, Alldredge BA, et al, editors. Applied Therapeutics: The Clinical Use of Drugs. 9th ed. Philadelphia, PA: Lippincott Williams and Wilkins; 2009.

23. Baxter K, editor. Stockley's Drug Interactions Pocket Companion.1st ed. London, UK: Pharmaceutical Press; 2011.

24. Reuters T. MICROMEDEX(R) Healthcare Series; DRUG-REAX ${ }^{\circledR}$ Interactive: Drug Interactions. 1974-2010;146.

25. Franklin B, O'Grady K, Donyai P, Jacklin A, Barber N. The impact of a closed-loop electronic prescribing and administration system on prescribing errors, administration errors and staff time: a before and after study. Qual Saf Health Care. 2007;16(4):279-284.

26. Kane-Gill SL, Kowiatek JG, Weber RJ. A comparison of voluntarily reported medication errors in intensive care and general care units. Qual Saf Health Care. 2010;19(1):55-59.

27. Morimoto T, Sakuma M, Matsui K, et al. Incidence of Adverse Drug Events and Medication Errors in Japan: the JADE Study. J Gen Intern Med. 2010;26(2):148-153.

28. Benkirane RR, Abouqal R, Haimeur CC, et al. Incidence of adverse drug events and medication errors in intensive care units: a prospective multicenter study. J Patient Saf. 2009;5(1):16-22.

29. Shulman R, Singer M, Goldstone J, Bellingan G. Medication errors: prospective cohort study of hand-written and computerized physician order entry in the intensive care unit. Crit Care. 2005;9(5):R516-R521.

30. Went K, Antoniewicz P, Corner DA, et al. Reducing prescribing errors: Can a well-designed electronic system help? J Eval Clin Pract. 2010; 16(3):556-559.

31. Vessal G. Detection of prescription errors by a unit-based clinical pharmacist in a nephrology ward. Pharm World Sci. 2010;32(1):59-65.

32. Sabry NA, Farid SF, Abdel Aziz EO. Role of the pharmacist in identification of medication related problems in the ICU: a preliminary screening study in an Egyptian teaching hospital. Aust J Basic and Appl Sci. 2009;3(2):995-1003.
Journal of Multidisciplinary Healthcare

\section{Publish your work in this journal}

The Journal of Multidisciplinary Healthcare is an international, peerreviewed open-access journal that aims to represent and publish research in healthcare areas delivered by practitioners of different disciplines. This includes studies and reviews conducted by multidisciplinary teams as well as research which evaluates the results or conduct of such teams or

\section{Dovepress}

healthcare processes in general. The journal covers a wide range of areas and welcomes submission from practitioners at all levels, from all over the world. The manuscript management system is completely online and includes a very quick and fair peer-review system. Visit http://www.dovepress.com/testimonials.php to read real quotes from published authors. 